\title{
Industry 4.0 and Lean Production - A Matching Relationship? An analysis of selected Industry 4.0 models
}

\author{
Christian Leyh, Stefan Martin \\ Technische Universität Dresden \\ Chair of Information Systems, esp. IS in \\ Manufacturing and Commerce \\ Helmholtzstr. 10, 01069 Dresden, Germany \\ Email: Christian.Leyh@tu-dresden.de
}

\author{
Thomas Schäffer \\ University of Applied Sciences Heilbronn \\ Faculty of Business Administration \\ Max-Planck-Str. 39, 74081 Heilbronn, Germany \\ Email: Thomas.Schaeffer@hs-heilbronn.de
}

\begin{abstract}
The increasing digitalization of business and society has led to drastic changes within companies. Nearly all enterprises are facing enormous challenges dealing with topics such as Industry 4.0/Industrial Internet. With the goal of supporting companies to handle these challenges and "move" in an Industry 4.0 environment, several frameworks or reference models already exist. Here, we share the results of a detailed analysis of selected Industry 4.0 models. In particular, we foster in our analysis Lean Production aspects since the basic principles of Lean Management/Lean Production in existence since the 1980s have yielded appropriate measures to optimize production. These principles can and should be addressed and included by Industry 4.0 models as well. Our study provides a classification of 31 Industry 4.0 models/frameworks as well as the identification of needs for further research to enhance existing Industry 4.0 models more holistically.
\end{abstract}

\section{Motivation AND OBJECTIVES}

C. onsidering the evolution of technology, digitalization/digital transformation provides manifold opportunities to support or even renew business processes by using technological solutions. These advanced technological opportunities, especially the merging of the physical with the digital world, result in new fundamental paradigm shifts that affect all sectors of industry. Companies must handle global digital networks, improve automation of individual or even all business processes, and reengineer existing business models to gain momentum in digital innovation. [1]-[3].

To appropriately deal with this adjusted management, communication concepts have become or will become highly important. In many parts of society, the Internet of
Things (IoT) has already established itself as an interlinked communication network to connect value chains. Examples include package tracking and vital data logging via Smartwatch or Smart Home control within domestic environments. This development is accompanied by increasingly short and individual life cycles of products that consequently lead to new production requirements. Transferring the approaches of the IoT to companies resulted in the concept of Industry 4.0 by connecting production with the internet, leading to an increasing digitization of products and systems associated with their interconnectedness [4]-[6].

An analysis using the "Google Trends" tool (see Figure 1) shows that interest in the field of Industry 4.0 has never been stronger than in the last few years. However, especially for those companies willing to use/integrate Industry 4.0 in their production, this integration is not a trivial task. Different reference models, frameworks and Industry 4.0 architectures have emerged to support companies acting in the field of Industry 4.0. Using these tools should enable companies to structure their business process appropriate regarding Industry 4.0 requirements.

Therefore, aim of this study was to analyze selected architectural/reference models of Industry 4.0. We characterized these models according to the basic principles of Lean Management/Lean Production since these approaches have existed since the 1980s and offer appropriate measures to optimize production. In our opinion, these approaches should be addressed and included by Industry 4.0 models as well.

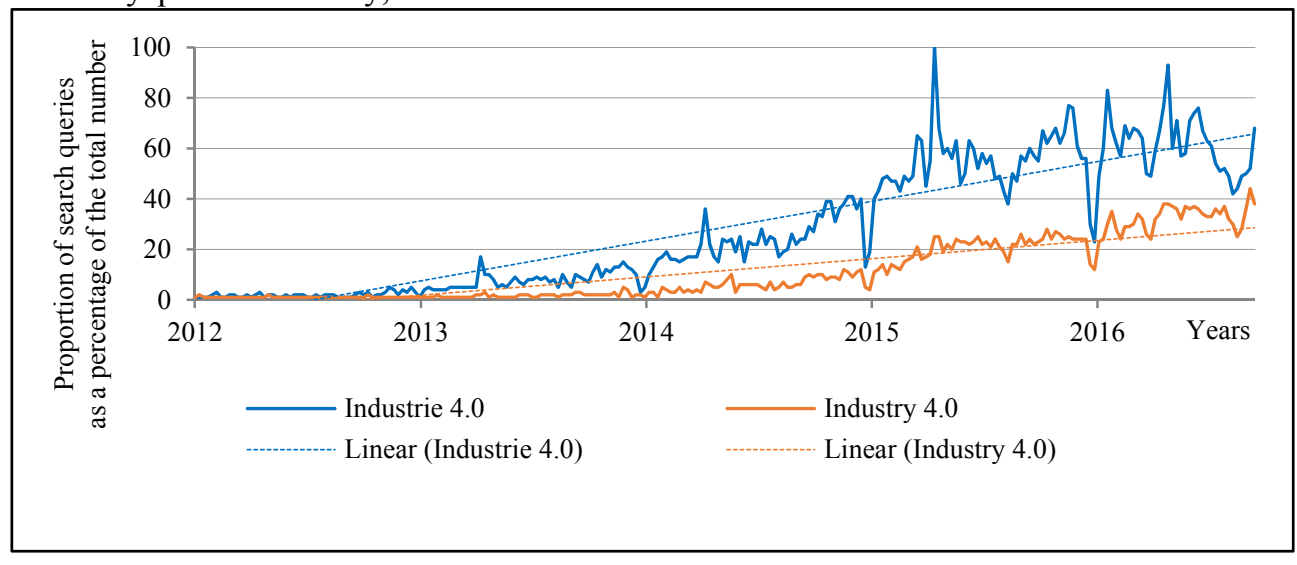

Fig. 1. Search queries for the terms "Industrie 4.0" and "Industry 4.0" on Google since 2012 
This study is guided by two research questions:

Q1: What organizational and technical reference models exist for Industry 4.0 ?

Q2: What relationship can be established between the reference models and Lean Production?

In order to answer those questions, we set up a study based on a systematic literature analysis. The aim of the literature analysis was to describe, summarize, evaluate, clarify and integrate aspects focusing Industry 4.0 and/or Lean Production. Selected study results will be presented in this paper. The paper is composed of four sections: 1) an introduction, 2) an overview of the conceptual background of the key terms "Industry 4.0" and "Lean Production," 3) our literature analysis (its methodology and selected results) and 4) a summary and aspects for future research.

\section{CONCEPTUAL BACKGROUND}

\section{A. Industry 4.0}

The term Industry 4.0 or the Industrial Internet is characterized as the fourth stage of the industrial revolution and consists of an increasing interconnectedness of products and systems. Focusing on the enhancement of the automation, flexibility, and individualization of products, production, and the connected business processes [7], Industry 4.0 aims to connect the physical and virtual worlds.

From a production perspective, Industry 4.0 is understood as the movement of intelligent workpieces that independently coordinate their paths through a factory. Machines are able to "realize" these tracks and communicate in real time with the corresponding warehouse. Information is primarily used to assess and control current processes [8]. However, a universal definition for the term Industry 4.0 does not exist. Therefore, we defined a working definition to serve as the foundation for our research, and we also used this definition in other related Industry 4.0 articles (e.g., [1], [5]): Industry 4.0 describes the transition from centralized production towards production that is very flexible and self-controlled.
Within this production, the products, all affected systems, and all of the process steps of the engineering, are digitized and interconnected to share and pass information and to distribute this information along the vertical and horizontal value chains and beyond in extensive value networks.

The fact that companies have not yet implemented many parts of Industry 4.0 is shown in Table I. Based on these data, independence is to be promoted at all levels; such independence can only be achieved through better communication (an essential part of Lean Production).

\section{B. Lean Production}

Lean Production/Lean Management already existed prior to the introduction of the concept of Industry 4.0. This form of production management was first seized on by Taiichi Ono in 1978, who was responsible for the production of the Japanese automotive manufacturer Toyota [9]. After the end of World War II, Toyota noticed that American car manufacturers were able to produce nine times as much as Japanese car manufacturers over the same time period because they manufactured large batch sizes in order to compensate for long set-up times. Such manufacturing was not possible for Toyota, however, because its production volume was too small. Therefore, Toyota implemented measures to achieve a leaner production (see [10]). In total, this concept led to a paradigm shift: Lean Production is now defined as a third production system design since it is neither mass production nor manual work [11].

The basic principle of Lean Production is based on the avoidance of eight causes of waste. These causes are summarized by [10] as transport, storage, accessibility of processes, unnecessary movement, waiting times, overproduction, tight tolerances, defects and, above all, unused skills of the employees. In addition, [12] classifies three central principles of Lean Production: Kaizen, Total Quality Management (TQM) and Business Process Reengineering $(B P R)$ (for a detailed description of this principles see [12]).

\section{TABLE I.}

COMPARISON OF A FACTORY TODAY AND AN INDUSTRY 4.0 FACTORY [14]

\begin{tabular}{|c|c|c|c|}
\hline & & $\begin{array}{c}\text { Today's } \\
\text { Manufacturing }\end{array}$ & $\begin{array}{c}\text { Industry } 4.0 \\
\text { Manufacturing }\end{array}$ \\
\hline \multirow{2}{*}{$\begin{array}{l}\text { Component } \\
\text { (e.g., sensor) }\end{array}$} & Key attributes & precision & $\begin{array}{c}\text { independent action based on own } \\
\text { predictions }\end{array}$ \\
\hline & Key technologies & $\begin{array}{l}\text { smart sensors and } \\
\text { fault detection }\end{array}$ & $\begin{array}{l}\text { degradation monitoring and remaining } \\
\text { useful life prediction }\end{array}$ \\
\hline \multirow{2}{*}{$\begin{array}{c}\text { Machine } \\
\text { (e.g., controller) }\end{array}$} & Key attributes & $\begin{array}{l}\text { producibility and performance (quality } \\
\text { and throughput) }\end{array}$ & $\begin{array}{l}\text { independent action based on own } \\
\text { predictions and comparison with } \\
\text { inventory data }\end{array}$ \\
\hline & Key technologies & $\begin{array}{l}\text { condition-based monitoring and } \\
\text { diagnostics }\end{array}$ & $\begin{array}{l}\text { operating time recording with } \\
\text { predictive health monitoring }\end{array}$ \\
\hline \multirow{2}{*}{$\begin{array}{c}\text { Manufacturing System } \\
\text { (e.g., manufacturing } \\
\text { execution systems) }\end{array}$} & Key attributes & $\begin{array}{l}\text { productivity and overall equipment } \\
\text { effectiveness }\end{array}$ & $\begin{array}{l}\text { Independent configure, maintain and } \\
\text { organize }\end{array}$ \\
\hline & Key technologies & $\begin{array}{l}\text { lean operations: work and waste } \\
\text { reduction }\end{array}$ & $\begin{array}{c}\text { low-maintenance, self-adapting } \\
\text { production systems }\end{array}$ \\
\hline
\end{tabular}




\section{Lean Production - Lean Automation - Industry 4.0}

Kolberg and Zühlke describe Industry 4.0 as a further development of Computer Integrated Manufacturing (CIM) and therefore as a network approach, which is complemented by CIM via communication and information technology. This approach is supported by the integration of Cyber Physical Systems [13]. These systems are a combination of two essential elements, which are the control of processes with the help of integrated software systems and the network of these software systems. With these systems, Lean Automation can be implemented in order to support and expand the approaches and concepts of Lean Production. The objectives of short lead times with minimal costs and the highest quality remain unchanged. Consequently, it is possible to provide a company-wide representation of the actual situation in real time and to enable simulation-based optimization measures based on decentralized control systems. Each workpiece is therefore clearly identifiable. Optimization measures and new services can be created from the resulting data.

In addition, the employee becomes the smart operator of production. The smart operator is, for example, notified by means of e-mail or SMS in the event of a fault reported by sensors, therefore reducing the time that elapses between the occurrence of the error and a fix being implemented. At the same time, the enterprise system makes suggestions for troubleshooting. [13].

\section{LITERATURE ANALYSIS}

As shown in Section II, Industry 4.0 and Lean Management/Lean Production are complex concepts that appear to possess similarities. To investigate these aspects, we set up a study approach to contrast those two concepts. Since Lean Production is a mature concept and Industry 4.0 is an emerging topic, we conducted a systematic literature review to identify current papers dealing with the area of Industry 4.0. After identifying and analyzing the Industry 4.0 papers, we compared and contrasted identified Industry 4.0 frameworks and models with important aspects and approaches of Lean Production/Lean Management.

\section{A. Methodology}

This systematic literature analysis is based on four steps according to [15], [16].

Step 1 - Selection of databases and search terms: To obtain a broad overview of the topic, we selected the databases ScienceDirect as well as Academic Search Complete and Business Source Complete. In addition, we used Google Scholar to identify articles may be not listed in scientific databases. The search fields for the database search were limited to the abstract, title and keywords. The search terms stemmed from a short preliminary search according to [16], resulting in the following search string:

TITLE-ABSTR-KEY("industrie 4.0" OR "industry 4.0" OR "fourth industrial revolution" OR "smart factory" OR "digital factory") and TITLE-ABSTR-KEY("framework" OR "scheme" OR "structure" OR "model").

Step 2 - Implementation of practical screening criteria: In step 2, we classified journal papers, conference papers and reports. We did not apply any temporal restrictions to our searches. We sought a general reference model for Industry 4.0 or, at least, Industry 4.0 concepts, frameworks, and approaches to a large extent. Therefore, articles were excluded that dealt only indirectly with Industry 4.0 or only with a single partial aspect of Industry 4.0 such as Big Data. All of the identified papers were transferred in the literature management software Zotero. Next, we used the Zotero's functionality to perform a duplication check.

Step 3 - Implementation of methodological screening criteria and Step 4 - Synthesis of the results: In these steps, a deeper analysis of the papers that were not excluded during the practical screening was conducted. First, the papers were classified according to basic criteria:

\begin{tabular}{|cl|}
\hline 1 & $\begin{array}{l}\text { Manufacturing environment: Does the model/the paper } \\
\text { focus on the manufacturing industry? }\end{array}$ \\
& $\begin{array}{l}\text { Industry } 4.0 \text { concept: Does the paper } \\
\text { present/discuss/evaluate a reference model that covers all } \\
\text { aspects of Industry } 4.0 \text { ? Or are only partial aspects of } \\
\text { Industry } 4.0 \text { addressed? }\end{array}$ \\
3 & $\begin{array}{l}\text { Does the model address software and/or hardware aspects } \\
\text { of Industry } 4.0 \text { ? }\end{array}$ \\
4 & $\begin{array}{l}\text { To what extent are Lean Production principles included } \\
\text { and addressed in the reference model? }\end{array}$ \\
5 & $\begin{array}{l}\text { To what extent are business applications or enterprise } \\
\text { systems explicitly fostered in the model? }\end{array}$ \\
6 & $\begin{array}{l}\text { Can the paper be classified as narrative article or merely } \\
\text { as examining statistical and mathematical aspects? }\end{array}$ \\
7 & $\begin{array}{l}\text { Is an evaluation presented and discussed regarding the } \\
\text { suitability and fit of the model in terms of Industry } 4.0 \\
\text { requirements? }\end{array}$ \\
\hline
\end{tabular}

To rate the papers according these criteria/questions, we used Harvey Balls with the differentiation shown in Table II.

TABLE II.

CRITERIA CLASSIFICATION

\begin{tabular}{|c|l|}
\hline Symbol & \multicolumn{1}{|c|}{ Description } \\
\hline 0 & Criterion is not addressed \\
\hline 0 & Criterion is addressed indirectly \\
\hline & Criterion is mentioned \\
\hline & Criterion is partially addressed \\
\hline & Criterion is fully addressed \\
\hline
\end{tabular}

In addition to the seven merely general criteria, we also assessed the models using the four concrete implementation requirements of Industry 4.0 postulated by different German national associations (e.g., VDMA: Mechanical Engineering Industry Association; Bitkom: Federal Association for Information Technology, Telecommunications and New 
Media; ZVEI: German Electrical and Electronic Manufacturers' Association) (see [6]):

$\begin{array}{|cl|}8 & \text { The extent of horizontal integration across value networks } \\ 9 & \text { The extent of vertical integration in the company } \\ 10 & \begin{array}{l}\text { The extent of product lifecycle management (PLCM) and } \\ \text { consistency of engineering }\end{array} \\ 11 & \begin{array}{l}\text { The extent of the "human factor" - the employee as a } \\ \text { conductor in the value networks }\end{array}\end{array}$

\section{B. Selected Results}

The search in the aforementioned databases with the presented search string yielded a total of 166 papers. Nine out of the 166 papers were duplicates and listed in more than one database. Therefore, those papers were excluded from the deeper screening. After practical screening of the remaining 157 papers, 31 papers were identified as fostering an Industry 4.0 framework or model according to our criteria. All of the papers that passed step 2 and were included in the methodological screening were published no earlier than 2010, which again emphasizes the relevance and topicality of this topic. We then screened these 31 articles carefully to assess the criteria of step 3. An example of the assessment of three selected papers is provided in the Appendix in Table IV. Selected results will be discussed in the following paragraphs. However, a complete assessment of all articles as well as the entire reference list of these papers will not be part of this article, but will be provided by the authors upon request or can be downloaded as supplementary material (see Table IV).

Twenty-seven out of the 31 articles focused on the manufacturing industry. The remaining articles dealt with, for example, the service sector, the construction sector and issues of cooperation in the value chain. During the deeper analysis, it became clear that 15 of the 31 articles presented or discussed an Industry 4.0 approach with a holistic focus and that 16 papers addressed specific partial aspects of Industry 4.0. In addition, it was striking that a discussion of software architectures prevailed in many of the articles. Hardware issues and aspects were not solely discussed and appeared in combination with software aspects.

Considering Lean Production, only three articles (Table IV, no. 4, 6, and 12) actively addressed and incorporated Lean Production in an Industry 4.0 setting to a full extent (in regard to our criteria). Although Lean Production was often noted (as discussed in Section II) to be one of the foundations for Industry 4.0, most related concepts in the identified 31 articles touched on only marginal aspects of Lean Production or did not focus on this principles in combination with Industry 4.0. Regarding the Industry 4.0 implementation requirements (criteria 8-11), we noted that vertical integration was the main subject in 13 out of 15 articles that provided a holistic Industry 4.0 model. On the other hand, the integration of employees was least often noted as the main paper topic. Table III gives a short summary of these the articles assessment.
TABLE III.

SHORT CATEGORIZATION OF THE IDENTIFIED ARTICLES

\begin{tabular}{|l|c|}
\hline Category of articles & No. of papers \\
\hline $\begin{array}{l}\text { Relevant in the sense of the research } \\
\text { questions }\end{array}$ & 31 \\
\hline $\begin{array}{l}\hookrightarrow \text { No holistic Industry } 4.0 \text { reference } \\
\text { model included }\end{array}$ & 16 \\
\hline $\begin{array}{l}\hookrightarrow \text { Holistic Industry } 4.0 \text { reference model } \\
\text { included }\end{array}$ & 15 \\
\hline $\begin{array}{c}\hookrightarrow \text { Lean Production principles } \\
\text { addressed as a main topic }\end{array}$ & 3 \\
\hline $\begin{array}{c}\hookrightarrow \text { No Lean Production principles } \\
\text { addressed as a main topic }\end{array}$ & 11 \\
\hline $\begin{array}{c}\hookrightarrow \text { Lean Production principles are } \\
\text { addressed in a medium to large } \\
\text { extent but not as a main topic }\end{array}$ & 1 \\
\hline
\end{tabular}

\section{Discussion AND CONCLUSION}

In summary, we identified several models and frameworks addressing the complex field of Industry 4.0 and have provided a first answer to research question Q1. However, not all models dealt with this topic in a holistic way; some instead focused on specific aspects or requirements of Industry 4.0. Hence, a common goal could be identified throughout all of the papers. The (explicit or indirect) stated goal was always to reduce the cost per unit produced. It was also crucial for all models and often discussed in the papers that communication (in three relationships: man-man, machine-man and, above all, machine-machine) was viewed as especially important for the further development and appropriate implementation of Industry 4.0. Machine-machine communication has an even larger impact because in Industry 4.0 communication and information sharing forms an essential foundation for autonomous machine decisions. A primary conclusion from this analysis is that the use of appropriate information and communication technology (ICT) is a crucial factor in Industry 4.0 environments, as has been also stated by several authors (e.g., [2], [3], [5]).

Regarding research question Q2, it became obvious that the Lean Management/Lean Production principles were not often addressed in Industry 4.0 models. Despite the fact that those aspects are often viewed as a basis for Industry $4.0 \mathrm{im}$ plementation, they were not integrated in the respective models nor were they discussed in connection with these models. Vertical integration was the main aspect in the identified models, and it also appeared in combination with horizontal integration aspects. This result also supports the fact that appropriate ICT is essential for Industry 4.0.

Those results motivate further research. First of all, it will be a challenge for enterprises to move in the field of Industry 4.0 and identify and implement the appropriate ICT. Therefore, in addition to the identified models more general ICT maturity models are needed (focusing Industry 4.0 requirements) and approaches for an appropriate master data management in the entire value networks. Several models re- 
garding these issues already exist. Those models deal with, e.g., enterprise system landscapes for Industry 4.0 (e.g., [5]), organizational aspects (e.g., [8]) and system-specific aspects in detail (e.g., [17]). However, mapping these maturity models is necessary to combine their different points of view. Different level assignments and dimensions between these models should be developed to enable companies to fully classify themselves in terms of Industry 4.0 requirements in all levels of their enterprise. With this work, companies will be able to determine their overall maturity in the field of Industry 4.0. In addition, the aspects of consistency of engineering and the employee itself as well as the evolution of work (often termed "Work 4.0") should be addressed in those models as well. It would be interesting to enhance and further develop existing Lean Production methodologies such as Kanban or Kaizen with regard to their Industry 4.0 suitability since these approaches are already designed in their structure for self-organization and automation (a key issue of Industry 4.0). In addition, the human factor must be better integrated into existing models since employees will remain an integral part of the processes.

In summary, despite the fact that there are already several existing frameworks and reference models considering Industry 4.0 environments there are still issues that can be viewed as unsolved or at least not adequately addressed. Therefore, further research is necessary to combine existing approaches with additional key aspects of Industry 4.0.

\section{REFERENCES}

[1] K. Bley, C. Leyh, and T. Schäffer, "Digitization of German Enterprises in the Production Sector - Do they know how 'digitized' they are?," in Proc. of the 22nd Americas Conf. on Inf. Syst. (AMCIS 2016), 2016.

[2] S. Mathrani, A. Mathrani, and D. Viehland, "Using enterprise systems to realize digital business strategies," Journ. of Enterprise Inf. Management, vol. 26, no. 4, pp. 363-386, 2013, doi: 10.1108/JEIM-01-2012-0003.

[3] M. Pagani, "Digital Business Strategy and Value Creation: Framing the Dynamic Cycle of Control Points," MIS Q., vol. 37, no. 2, pp. 617-632, 2013.

[4] G.R. Bitran, S. Gurumurthi, and S.L. Sam, "The need for third-party coordination in supply chain governance," MIT Sloan Management Review, vol. 48 , no.3, 2007, pp. 30-37.

[5] C. Leyh, T. Schäffer, K. Bley, and S. Forstenhäusler, "Assessing the IT and Software Landscapes of Industry 4.0-Enterprises: The Maturity Model SIMMI 4.0," in Information Technology for Management: New Ideas and Real Solutions (Lecture Notes in Business Information Processing, LNBIP, Vol. 277), E. Ziemba Ed. Heidelberg, Berlin, New York: Springer, 2017, pp. 103-119, doi: 10.1007/978-3-319-53076-5_6.

[6] BITKOM, VDMA, and ZVEI, Umsetzungsstrategie Industrie 4.0: Ergebnisbericht der Plattform Industrie 4.0, Berlin, 2015.

[7] C. Lemke and W. Brenner, Einführung in die Wirtschaftsinformatik: Band 1: Verstehen des digitalen Zeitalters, 2015th ed. Heidelberg, Germany: Springer, 2014, doi: 10.1007/978-3-662-44065-0.

[8] T. Kaufmann, Geschäftsmodelle in Industrie 4.0 und dem Internet der Dinge: der Weg vom Anspruch in die Wirklichkeit, Wiesbaden, Germany: Springer, 2015, doi: 10.1007/978-3-658-10272-2.

[9] T. Ōno, Das Toyota-Produktionssystem [das Standardwerk zur Lean Production], 3rd ed. Frankfurt am Main, Germany: Campus, 2013, translated from W. Hof.

[10] T. Ōno, Toyota production system: beyond large-scale production, Taylor \& Francis, 1988, translated from C.B. Rosen.

[11] I.D. Tommelein, "Journey towards lean construction: pursuing a paradigm shift," Journal of Construction Engineering and Management, vol. 141, no. 6, 2014, doi: 10.1061/(ASCE)CO.1943-7862.0000926.

[12] H. Oeltjenbruns, Organisation der Produktion nach dem Vorbild Toyotas: Analyse, Vorteile und detaillierte Voraussetzungen sowie die Vorgehensweise zur erfolgreichen Einführung am Beispiel eines globalen Automobilkonzerns, Aachen, Germany: Shaker, 2000.

[13] D. Kolberg and D. Zühlke, "Lean Automation enabled by Industry 4.0 Technologies," IFAC-PapersOnLine, vol. 48, no. 3 (15th IFAC Symposium on Inf. Control Problems in Manuf.: INCOM 2015), pp. 1870-1875, 2015.

[14] J. Lee, B. Bagheri, and H.-A. Kao, "Recent advances and trends of cyber-physical systems and big data analytics in industrial informatics," in Proc. of Int. Conf. on Industrial Informatics (INDIN 2014), 2014.

[15] A. Fink, Conducting research literature reviews : from the internet to paper, 4th ed. Los Angeles: SAGE Publ., 2014.

[16] P. Fettke, "State of the Art of the State of the Art: A study of the research method "Review" in the information systems discipline," Wirtschaftsinformatik, vol. 48, no. 4, pp. 257-266, 2006, doi: 10.1007/s11576-006-0057-3

[17] BMWi, Erschliessen der Potenziale der Anwendung von "Industrie 4.0" im Mittelstand. Studie im Auftrag des Bundesministerium für Wirtschaft und Energie (BMWi), Mülheim an der Ruhr, Germany: agiplan $\mathrm{GmbH}, 2015$.

\section{APPENDIX - TABLE IV.}

EXAMPLE - CATEGORIZATION OF THE IDENTIFIED ARTICLES ACCORDING TO THE CLASSIFICATION CRITERIA

\begin{tabular}{|c|c|c|c|c|c|c|c|c|c|c|c|c|}
\hline \multirow[b]{2}{*}{ No. } & \multirow[b]{2}{*}{ Reference } & \multicolumn{7}{|c|}{ General criteria } & \multicolumn{4}{|c|}{$\begin{array}{c}\text { Industry } 4.0 \text { implementation } \\
\text { aspects (see [6]) }\end{array}$} \\
\hline & & 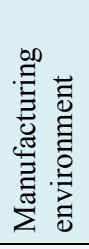 & 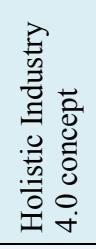 & 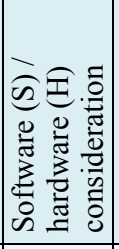 & 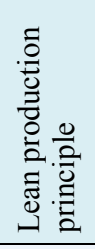 & 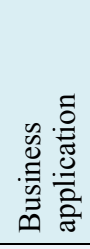 & 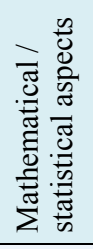 & 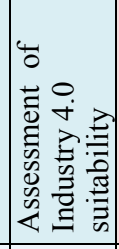 & 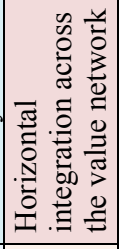 & 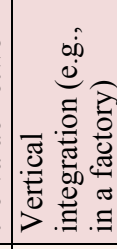 & 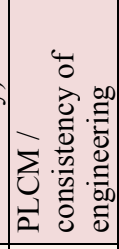 & 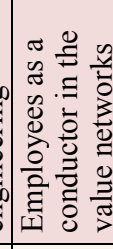 \\
\hline 4 & Brettel et al. 2016 & & $\bigcirc$ & $\mathrm{S}$ & & O & ( & 0 & 0 & ( & & 0 \\
\hline 6 & Diez et al. 2015 & & 0 & $\mathrm{~S}$ & & $\theta$ & & $\theta$ & ( & & C & $\theta$ \\
\hline 12 & Long et al. 2016 & & & $\mathrm{~S}$ & (1) & (1) & $\theta$ & $\theta$ & (1) & & 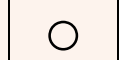 & (1) \\
\hline
\end{tabular}

